\title{
On creating and using representations of mathematics teaching in research and teacher development
}

\author{
Introduction to this issue
}

\author{
Patricio Herbst • Daniel Chazan
}

Accepted: 2 January 2011/Published online: 20 January 2011

(C) FIZ Karlsruhe 2011

For years, researchers and teacher educators worldwide have used classroom video records (Davis, 1967; Lampert \& Ball, 1998), samples of student work (Fosnot \& Dolk, 2001; Wilcox \& Lanier, 2000), narrative cases (Merseth, 1996, 2003; Smith, Silver, \& Stein, 2004), scenarios (Bishop \& Whitfield, 1972), and other artifacts (e.g., lesson plans) to engage teachers in discussions about teaching. The purposes of these artifacts have been diverse-from eliciting teacher thinking and pedagogical decision making (see Borko, Roberts, \& Shavelson, 2008), to learning to notice student ideas (van Es \& Sherin, 2002, 2008), to promoting particular pedagogies, techniques, or materials (Friel \& Carboni, 2000), to promoting discussion of how mathematical ideas emerge in classroom discourse (Borko, Jacobs, Eiteljorg, \& Pittman, 2008), and to making mathematics teaching practice available for international examination (Clarke, 2006; Stigler \& Hiebert, 1997). More recently, initially in service of research on teaching (Herbst \& Chazan, 2006; Herbst \& Miyakawa, 2008; Herbst, Nachlieli, \& Chazan, 2010) and then in service of teacher education (Chazan, Herbst, \& Sela, 2010; Herbst, Chazan, Chen, Chieu, \& Weiss, 2010), the Thought Experiments in Mathematics Teaching (ThEMaT) project has created and

The content of this introduction has been shaped by discussions during the first and second conferences Creating and Using Representations of Mathematics Teaching in Research and Teacher Education that took place in Ann Arbor, Michigan, August 23-25, 2009 and June 2010.

P. Herbst $(\square)$

University of Michigan, Ann Arbor, MI, USA

e-mail: pgherbst@umich.edu

D. Chazan

University of Maryland, College Park, MD, USA

e-mail: dchazan@umd.edu explored uses of animations and comic books using cartoon characters both in face to face and online settings (Chieu, Herbst, \& Weiss, 2010; see also http://grip.umich.edu/ themat).

This special issue attempts to foster a conversation that brings together a diversity of research and development efforts related to how such artifacts assist in the transaction of meanings about teaching. With the expression "representations of teaching" used in the title of the special issue, we designate a heterogeneous set of artifacts produced with different semiotic systems, artifacts that have at least three features in common:

(a) The artifacts are made of signs $^{1}$ that point to mathematics instruction (to teacher and students transacting mathematical ideas) as their object or referent (Peirce, 1955). These signs might be iconic such as the images of actual people captured in video or photography, but they might also be symbolic such as the language used to describe those people and their actions in a written case. In any case those signs represent in the sense that they call for or appeal to something other than themselves.

(b) The artifacts can be used in activity systems (Engestrom, 1999), where they become instruments for individuals (who might be learners of teaching or experts being interviewed) to engage in an objectoriented activity, such as the study of the features of a practice or the production of a possible action in practice.

\footnotetext{
${ }_{1}$ We are aware that Peirce at times would call this a sign-vehicle (or representamen) and would reserve the word sign for the complete triad of sign-vehicle, object, and interpretant. For simplicity, we refer to the triad here as sign, object, and interpretant.
} 
(c) In these activity systems, the artifacts are the milieu (feedback producer counterparts; Brousseau, 1997) of viewers or readers who, as they engage with these artifact, can immerse themselves in classroom instruction, in particular being able to anticipate how teacher and students could carry out classroom action before, after, or instead of the actions depicted.

Thus, as a provisional definition, we can say that representations of teaching include material artifacts that stand for mathematics instruction for sense-making individuals whose relationship with the artifacts are framed by an object-oriented, social situation (research or teacher development).

The value of such provisional definition, like that of any sacrificial draft, is that it opens a space for the gathering of diverse objects and for the discussion of their features, present or absent. In particular, Grossman et al. (2009) notions of representations, decompositions, and approximations of practice allude to ways in which particular artifacts can be used in different activity systems to support prospective teachers in learning to teach. That provisional definition also stresses that, as researchers on teaching or teacher educators, we are not solely interested in the media as much as in the relationship between media and messages, which we consider highly dependent on the actual response of viewers and readers to the stimuli and feedback of the media (see Chazan \& Herbst, 2011). Such provisional definition is also valuable because it enables the asking of questions about representations of mathematics teaching. In particular, scholars who work with representations of teaching have confronted problems of design, facilitation, navigation, archival, and analysis that are shared across the field.

In our call for proposals of manuscripts for this special issue, we solicited participation of scholars interested in one or more of those issues. We invited theoretical essays, literature reviews, design descriptions, or empirical studies that addressed one or more of the following issues opened up by the provisional definition provided above:

- On the notion of "representation of teaching:" What leverage is there in conceptualizing "representation of teaching" in general, as opposed to considering specific kinds of media and the specific uses that people put them to? How can general conceptualizations such as the provisional definition proposed above be strengthened or improved and used?

- On teaching as "the thing represented:" The definition above includes the participants of the act of teaching (teacher, students, mathematics) as well as their interactions over time. What other aspects of this professional work might be pointed to by way of representations of teaching? And how can those aspects of teaching be conceptualized in ways that can aid the production of representations?

- On the symbol systems used to create representations of teaching: From particular variations in the use of language (such as using certain words and avoiding others) to the design of graphic characters to point to aspects of practice that matter in the work of teaching, what considerations are needed and how can these be decided upon and improved?

- On the workflows that are used to create representations of teaching with different symbol systems: From choosing and editing footage or transcript to composing graphically and creating dialogue, or from metaphors of paring down to building up, what are ways in which the creative work is done, how can these workflows be specified and improved?

- On the creation of the artifacts used in representations of teaching: What are problems encountered, recommended practices, and available tools? In particular, what ideas and tools from video production, graphic design, user interface, theater, or fiction writing can assist the creative process?

- On the grain size and timescales of representations of teaching: What are the various scales at which action could be represented? Representations could point to objects in one or more grain sizes: instructional situations, instructional sequences, teaching skills, styles of teaching, the teaching of a particular curriculum or concept or the use of a particular curricular task, the teaching adapted to a particular context or group of students, etc., are examples of different grain sizes. What other grain sizes could be targeted by representations and how do grain size considerations mesh with the design of the symbol systems for such representations?

- On the multidimensionality of representations of teaching: While an artifact may be designed to represent teaching, since teaching involves attending to the mathematics being taught and to the cognition of the students' being taught, the artifact may just as much include representations of mathematics as well as of students cognition. Are there ways of coordinating these diverse dimensions of a representation? How does that multidimensionality affect design and use?

- On the need for representations of teaching in research on teaching, teacher development, or research on teacher education: For what semiotic relationships are these representations needed and how are they expected to do their job of counterpart to the viewer/reader? Are there principles, theories, or practices that can inform the design of the activity systems in which representations are partnered with their audience? 
- On different media used in representations of teaching: What are the advantages and disadvantages of printed text, video clips from actual lessons, animations of cartoon characters, comic strips, photo slide shows, or rehearsals of teaching tasks? Does the kind of media matter in what controls can be shared with the audience and what controls need to be managed centrally?

- On the social framing and purpose of those semiotic relationships: Some times audiences can be engaged with representations for the sake of eliciting (even consulting) their views on the professional work of teaching, as if they were experts being interviewed. Other times the purpose of such encounters has a more or less explicit educative purpose for the audience, as if they were students taking a class. What are the different purposes of enabling these relationships between representation and audience and what recurring social situations (or cultural scripts) can help frame those relationships?

- On the nature of the audience for a representation of teaching: To the extent that "representation of teaching" relies not just on a media artifact but also on a semiotic relationship with an audience, how can we think about that audience in terms of what is that audience enabled to do? From silently reading a case individually to watching an animation in a group while anybody can pause the play to make a comment, how can we think of audience configurations and their capabilities for interacting with the media?

- On the facilitation of discussions or investigations assisted by representations of teaching: What are the possibilities and demands of a pedagogy assisted by representations? What considerations are needed to make when framing the encounter of an audience with an artifact, depending on who the audience is and the specifics of the artifact? What else can be done beyond the general "watch and we'll talk"? How does the multidimensionality of representations (the fact that they involve representations of mathematics and of students' thinking as much as those of teacher action) feature in the organization of encounters with representations? In particular, does it help to organize an earlier encounter with the mathematics of the representation?

- On the kind of teaching being represented: Does it matter, and how does it matter, whether representations of teaching point to what purportedly exists in reality or to what is desirable from a particular viewpoint? Does this affect choices of media or facilitation and how so?

- On learning technologies to navigate representations of teaching: What is available and what is needed? Web 2.0 technologies have brought up the possibility for users to do more than read or view media artifacts- they can record, share, tag, comment, rate, index, and mix media artifacts. Are those capabilities useful in enabling the work with representations of teaching? What other capabilities are desirable?

- On the collection and dissemination of representations of teaching and their user support materials: What sorts of publication and archival practices can support wide usability and a range of kind of uses by researchers and teacher educators and their clients?

- On the analysis of data collected in response to representations: What frameworks and methodologies support analysis and aggregation of participants' responses to rich media representations? In particular, how can the timeline-dependent nature of responses to representations be preserved and built upon in analytic and synthetic practices?

- On the role that representations of teaching can play in international studies of teaching and international collaborations around the study of teaching and teacher education: How can representations of teaching enable discussions across differences in context?

- Teaching is knowledge-based and practice-based. Disciplinary textbooks such as those in mathematics and in psychology exhibit methods for communicating propositional knowledge. Practice, in particular the professional practice of teaching mathematics in classrooms, has increased its profile as a matter of study both for researchers and for future practitioners: Practice is no longer just a site for applying general principles or theories but also a source of complexities that need to be understood and managed in real time. What available methods are there for communicating teaching practice? And how can representations of teaching help in that task?

The present issue includes the articles that responded to that call. Needless to say, they address only some of the questions posed above, but they illustrate quite eloquently the potential of this set of issues. In addition to this introduction, the issue includes 14 papers written by 27 scholars; these scholars come from 11 different countries but are currently located in only 4 different countries. While we hope that future conversations about the creation and use of representations of mathematics teaching will include more colleagues from more countries, we offer this selection as a conversation starter.

Broadly speaking the articles in this issue can be organized in four groups. A first group addresses issues of representation. Among them Ann Ryu Edwards's article "Representing context in video records of practice for urban mathematics teacher education" considers how context can be made available to prospective teachers through video and challenges creators of representations to 
consider the challenge of doing so. In the same group Michael Weiss's article "Opening the closed text: The poetics of representations of teaching" proposes that animations of mathematics classroom scenarios can be considered instances of Eco's notion of the open work. Contributing to the theme of representations themselves, Jean-Philippe Maitre, Christian Dépret, Erica de Vries, and Jacques Baillé, in their article "Tacitation and implicitation: The construction of semiotic tools for representing mathematics teaching" further elaborate on the semiotic processes enabled by representations of teaching.

A second group of papers address the role of representations of teaching in the work of mathematics education research. Discussing the role of representations as instruments in research, the paper by Vilma Mesa and Patricio Herbst, "Designing representations of trigonometry instruction to study the rationality of community college teaching" outlines and illustrates the design process followed to construct the script of an animated scenario. The paper by Talli Nachlieli, "Co-facilitation of study groups around animated scenes: The discourse of moderator and researcher", examines the discourse of different facilitator roles in study group sessions and how they collaborate to sustain teachers' discussions of animations of instruction. Similarly, Gloriana González's paper, "Who does what?: A linguistic approach to analyzing teachers' reactions to videos," illustrates how Systemic Functional Linguistics provides tools that can be used for the analysis of dialogue produced in conversations about representations of teaching. Completing this group, Götz Krummheuer's paper, 'Representation of the Notion "Learning-as-Participation" in everyday Situations of Mathematics Classes' considers the fundamental issue of how abstract theoretical notions for the study of teaching and learning require more concrete representations in order to be operational in research.

A third group of articles discusses the roles of different kinds of representations of teaching in teacher education. Our paper "Using comics-based representations of teaching, and technology, to bring practice to teacher education courses" (written with co-authors Chia-ling Chen, Vu-Minh Chieu, and Michael Weiss) conceptualizes two dimensions of the different semiotic systems involved in existing representations of teaching and puts them to the service of a consideration of how prospective teachers might learn from interacting with cartoon-based representations. A variant of that theme is addressed in the paper by Vu-Minh Chieu and Patricio Herbst, "Designing an intelligent teaching simulator for learning by practicing in the practice of mathematics teaching;" these authors show what a virtual setting for learning to teach could look like and thus illustrate how preservice teachers could be engaged in what Grossman et al. (2009) call an "approximation of practice." Providing another example of an approximation of practice, the paper by Sandra Crespo, Joy Oslund, and Amy Parks, "Imagining mathematics teaching practice: Prospective teachers generate representations of a class discussion", shows the potential of dialogue creation by prospective teachers. Also in this section, the paper by Rosella Santagata and Jody Guarino titled "Using video to teach future teachers to learn from teaching" introduces a Lesson Analysis Framework and shows how the use of this framework helps build prospective teachers capacity to learn from video records of instruction. A comparable goal is sought in the paper by Hala Ghousseini and Laurie Sleep, "Making practice studyable," who describe various ways in which teacher educators can mediate the interaction of preservice teachers with representations of teaching.

The fourth set of papers examines the use of representations of practice in encounters with practicing teachers. Examining the use of animated classroom scenarios in an online forum associated with a geometry class for preservice and inservice secondary mathematics teachers, the paper by Deborah Moore-Russo and Janine Viglietti, "Teachers' reactions to animations as representations of geometry instruction," examines the content of mathematics discussions generated online in response to different animations. Finally, addressing the professional development of practicing teachers, the paper by Hilda Borko, Karen Koellner, Jennifer Jacobs, and Nanette Seago, titled "Using video representations of teaching in practice-based professional development programs", shows how programs that involve video-based representations of teaching can vary between being adaptive to context and being highly specified; they illustrate that distinction by describing two professional development programs.

As editors of this special issue, we see the issues raised by this set of papers as generative for future research and development. We are eager to see how our field will continue to explore the capacity of new technologies and older ones in relationship to understanding, reproducing, and reshaping mathematics teaching.

Acknowledgments We acknowledge the participants at both conferences. Those conferences as well as some of the ideas relayed in this introduction have been developed with the support of National Science Foundation grant ESI-0353285 to the authors. Opinions expressed here are solely those of the authors and do not represent the views of the foundation.

\section{References}

Bishop, A. J., \& Whitfield, R. C. (1972). Situations in teaching. Boston: McGraw-Hill.

Borko, H., Jacobs, J., Eiteljorg, E., \& Pittman, M. (2008). Video as a tool for fostering productive discussions in mathematics professional development. Teaching and Teacher Education, 24(2), $417-436$. 
Borko, H., Roberts, S., \& Shavelson, R. (2008). Teachers' Decision Making: from Alan J. Bishop to Today. In P. Clarkson \& N. Presmeg (Eds.), Critical Issues in Mathematics Education: Major contributions of Alan Bishop (pp. 37-67). New York: Springer.

Brousseau, G. (1997). In N. Balacheff, M. Cooper, R. Sutherland, \& V. Warfield (Eds. \& Trans.), Theory of didactic situations in mathematics: Didactique des mathématiques 1970-1990. Dordrecht, The Netherlands: Kluwer Academic Publishers.

Chazan, D., \& Herbst, P. (2011). Challenges of particularity and generality in depicting and discussing teaching. For the learning of mathematics. 33(1).

Chazan, D., Herbst, P., \& Sela, H. (2010). Instructional alternatives via a virtual setting: Rich media supports for teacher development. In O. Zaslavsky \& P. Sullivan (Eds.), Constructing knowledge for teaching secondary mathematics: Tasks to enhance prospective and practicing teacher learning. Springer (in press).

Chieu, V. M., Herbst, P., \& Weiss, M. (2010). Effect of an animated classroom story embedded in online discussion on helping mathematics teachers learn to notice. Journal of the Learning Sciences (in press).

Clarke, D. J. (2006). The LPS research design. In D. J. Clarke, C. Keitel, \& Y. Shimizu (Eds.), Mathematics classrooms in twelve countries: The insider's perspective (pp. 15-37). Rotterdam: Sense Publishers.

Davis, R. (1967). A modern mathematics program as it pertains to the inter-relationship of mathematical content, teaching methods, and classroom atmosphere (The Madison Project). Syracuse, NY: Syracuse University.

Engestrom, Y. (1999). Activity theory and individual social transformation. In Y. Engestrom \& R. Miettinen (Eds.), Perspectives in activity theory (pp. 19-38). Cambridge: Cambridge University Press.

Fosnot, C., \& Dolk, M. (2001). Young mathematicians at work: Constructing number sense addition and subtraction. Portsmouth, NH: Heinemann.

Friel, S., \& Carboni, L. (2000). Using video-based pedagogy in an elementary mathematics methods course. School Science and Mathematics, 100(3), 118-127.

Grossman, P., Compton, C., Igra, D., Ronfeldt, M., Shahan, E., \& Williamson, P. (2009). Teaching practice: A cross-professional perspective. Teachers College Record, 111(9), 2055-2100.

Herbst, P., \& Chazan, D. (2006). Producing a viable story of geometry instruction: What kind of representation calls forth teachers' practical rationality? In S. Alatorre, J. L. Cortina, M. Sáiz, \& A. Méndez (Eds.), Proceedings of the 28th annual meeting of the North American chapter of the international group for the psychology of mathematics education (Vol. 2, pp. 213-220). Mérida, México: Universidad Pedagógica Nacional.

Herbst, P., Chazan, D., Chen, C., Chieu, V. M., \& Weiss, M. (2010). Using comics-based representations of teaching, and technology, to bring practice to teacher education courses. ZDM-The International Journal of Mathematics Education (this issue).

Herbst, P., \& Miyakawa, T. (2008). When, how, and why prove theorems: A methodology to study the perspective of geometry teachers. ZDM-The International Journal on Mathematics Education, 40(3), 469-486.

Herbst, P., Nachlieli, T., \& Chazan, D. (2010). Studying the practical rationality of mathematics teaching: What goes into "installing" a theorem in geometry? Cognition and Instruction (in press).

Lampert, M., \& Ball, D. L. (1998). Teaching, multimedia, and mathematics: Investigations of real practice. New York: Teachers' College Press.

Merseth, K. (1996). Cases and case methods in teacher education. In J. Sikula (Ed.), Handbook of research in teacher education (pp. 722-744). New York: MacMillan.

Merseth, K. (2003). Windows on teaching math: Cases of middle and secondary classrooms. New York: Teachers College Press.

Peirce, C. S. (1955). Logic as semiotic: The theory of signs. In J. Buchler (Ed.), Philosophical writings of Peirce (pp. 98-119). New York: Dover (original work 1897).

Smith, M., Silver, E., \& Stein, M. K. (2004). Using cases to transform mathematics teaching and learning: Improving instruction in algebra. New York: Teachers' College Press.

Stigler, J., \& Hiebert, J. (1997). Understanding and improving classroom mathematics instruction: An overview of the TIMSS Video Study. Phi Delta Kappan, 78(1), 14-21.

van Es, E. A., \& Sherin, M. G. (2002). Learning to notice: Scaffolding new teachers' interpretations of classroom interactions. Journal of Technology and Teacher Education, 10, 571-596.

van Es, E. A., \& Sherin, M. G. (2008). Mathematics teachers' "learning to notice" in the context of a video club. Teaching and Teacher Education, 24(2), 244-276.

Wilcox, S., \& Lanier, P. (2000). Using assessment to reshape teaching: A casebook for teachers and teacher educators curriculum and staff development specialist. Hillsdale, NJ: Lawrence Erlbaum Associates. 